\title{
Construindo um modelo de avaliação epistêmica da Geografia com base em resolução de problemas
}

\author{
Construyendo una plantilla de evaluación epistêmica de la \\ Geografía con base en resolución de problemas
}

\section{Building a model of epistemic evaluation of Geography based on problem solving}

\author{
Rosana Figueiredo Salvi \\ salvi@uel.br \\ Universidade Estadual de Londrina
}

\begin{abstract}
Resumo: O presente trabalho busca alternativas de avaliação da Geografia tendo como base uma epistemologia pautada na visão de que ciência envolve resolução de problemas por diferentes Tradições de Pesquisa. Neste artigo, procura-se elucidar tais termos discutindo-se os pressupostos dos problemas conceituais e empíricos da ciência geográfica, ao mesmo tempo em que, partindo das teorias que respondem a tais problemas, procura-se delimitar diferentes Tradições de Pesquisa ao longo do desenvolvimento da Geografia.
\end{abstract}

Palavras-chave: Geografia. Avaliação epistêmica. Resolução de problemas. Tradições de Pesquisa.

Resumen: El presente trabajo búsqueda alternativas de evaluación de la Geografía teniendo como base una epistemologia pautada en la visión de que ciencia envuelve resolución de problemas por diferentes tradiciones de investigación. En este artículo, se busca elucidar tales hayamos discutiendo los presupuestos de los problemas conceptuales y empíricos de la ciencia geográfica, al tiempo que, partido de las teorías que responden la tales problemas, se busca delimite diferentes tradiciones de investigación al largo del desarrollo de la Geografía.

Palabras clave: Geografía. Evaluación epistêmica. Resolución de problemas. Tradiciones de investigación.

Abstract: This paper seeks alternatives to Geography assessments, based upon an epistemology abiding to the vision that science involves problem solving by different research traditions. In this article, we seek to elucidate such terms discussing the assumptions of conceptual and empirical problems of geographical science while, at the same time - addressing to the theories that would respond to such problems -, seeks to delimit different research traditions along the development of geographical science.

Keywords: Geography. Epistemic evaluation. Problem solving. Research traditions. 


\section{INTRODUÇÃO}

A influência das grandes tendências do pensamento geográfico foi se estendendo a partir de importantes fronteiras teóricas. Discutir tais fronteiras pelo viés de um modelo epistêmico é o que se almeja como proposta de investigação. Entretanto, estudos epistemológicos no campo da história e filosofia da ciência privilegiam estruturas hierarquizadas nas quais sobressaem ora a teoria, ora a metodologia, ora os valores ou metas da ciência. O modelo aqui defendido em princípio quebra essa hierarquização ao buscar estabelecer ao longo da história da Geografia diferentes posições reveladas mais fortemente pelas mudanças no trato da teoria, da metodologia e das metas perseguidas pelos estudos geográficos.

Sugere-se que as mudanças ocorridas possam ser avaliadas em função das respostas dadas aos problemas da Geografia por meio de suas teorias. Partindo de um ordenamento dos diferentes tipos de problemas conceituais e empíricos da ciência geográfica, buscase relacionar tal ordem a redes conceituais de modo que possam ser contextualizados (LAUDAN, 1977). Propõe-se uma análise de teorias a partir de duas esferas nas quais teoria tanto pode significar um conjunto de hipóteses que prediz e explica fenômenos, como também conjuntos de doutrinas ou proposições gerais, entendidas como Tradições de Pesquisa (LAUDAN, 1977).

O modelo que se almeja pode ser explicitado a partir da suposição de que a ciência geográfica em essência constitui-se numa atividade de resolução de problemas como as demais disciplinas científicas em geral. Aqueles sobre os quais a Geografia se debruça promovem a criação ou aproximação com teorias que de alguma forma os compreendem e explicam. O mesmo ocorre com seus respectivos métodos de análise e tratamento técnico de dados, compreendendo-se que a Geografia, partindo de certos problemas, subjaz seu campo de pesquisa com vista a firmar compromissos estabelecidos e demarcados por seus métodos e teorias. Procura-se com tal procedimento superar a demasiada abstração que envolve a noção de teoria.

Dois princípios iniciais comporiam essa base da estruturação científica da Geografia:

1) Para a ciência geográfica uma teoria é aceita se ela proporciona respostas plausíveis para problemas relevantes de ordem espaço-temporal.

2) Para avaliar os méritos das teorias para o avanço do conhecimento geográfico é razoável perguntar se constituem soluções adequadas a problemas importantes, mais do que se são verdadeiras, se estão corroboradas, bem confirmadas ou se são justificáveis no âmbito da epistemologia dominante no contexto histórico do momento.

3) A dialética desse entendimento situa-se no contraponto entre problemas do conhecimento geográfico - empíricos e conceituais - e respostas de nível teórico-metodológico que se dá para resolvê-los.

Expostos tais pressupostos, cabe explanar sobre os problemas que dizem respeito ao domínio do conhecimento geográfico. Estes se contextualizam no conjunto das mudanças que ocorrem no cerne do pensamento geográfico de acordo com metas e objetivos 
de pesquisas e também em termos de metodologia. Obviamente, nesse conjunto, mudam também as Tradições de Pesquisa e suas respectivas teorias.

Sendo assim, as perguntas que norteiam essa pesquisa são:

Como e quais problemas podem ser levantados no conjunto das pesquisas geográficas?

a) Por meio de objetivos, teorias e metodologias de pesquisa, de que maneira é possível vincular problemas da Geografia a diferentes Tradições de Pesquisa?

b) Quais compromissos científicos podem ser identificados em razão dos problemas que se procura resolver no decorrer da história da Geografia?

c) Como tratar igualmente problemas conceituais e empíricos a partir de diferentes Tradições de Pesquisa em Geografia?

Ao se investigar a evolução do conhecimento geográfico, mudanças observadas dificilmente se tornam inteligíveis no âmbito de uma epistemologia hierarquizada, uma vez que se relacionam no conjunto dos valores, teorias e metodologia da pesquisa. Buscar, por conseguinte, avançar no sentido de responder sobre tais mudanças no cerne da teorização em Geografia implica uma alternativa de compreensão e avaliação epistêmica dos compromissos e valores científicos assumidos ao longo de sua história. O presente trabalho inspira-se, sobretudo, no aspecto levantado por Laudan (1977) de que nenhuma das propostas do enfoque histórico na Filosofia da Ciência, com seus estudos de caso e modelos teóricos de análise, foi devidamente testada. Busca-se, pois, como é possível investigar o conhecimento geográfico, sua história e evolução de teorias por meio de um modelo reticulado por crenças factuais, metodológicas e valorativas, dependentes uma das outras e das mudanças que sofrem ao longo do tempo. Tal proposta apresenta-se num nível introdutório, conhecendo-se a necessidade de maiores esforços nesse empenho. Limita-se, pois, em averiguar no campo da Geografia noções de teoria vinculadas a diferentes Tradições de Pesquisa e ao contexto de seus problemas a partir de exemplares selecionados. Sugere-se a elaboração de um modelo de avaliação que seja conduzido por componentes inter-relacionados numa rede composta pelos objetivos da pesquisa geográfica, pelos métodos utilizados para alcançar esses objetivos e pelas teorias ou afirmações factuais que resultam da aplicação de tais métodos. Quer-se chegar aos valores cognitivos necessários para firmar compromissos envoltos nas pesquisas e também avaliar se as metas foram alcançadas em termos de afirmações factuais (teorias) pelos métodos.

\section{Problemas Conceituais e Empíricos da Geografia}

Sobre os problemas que dizem respeito ao domínio do conhecimento geográfico, estes se contextualizam em termos valorativos no conjunto das mudanças, de acordo com metas e objetivos da pesquisa geográfica e também em termos de sua metodologia.

Propõem-se com base em Laudan (1986) duas categorias de problemas, os chamados problemas conceituais (definidos como aqueles apresentados por uma teoria) e empíricos (de ordem operacional das pesquisas), argumentando que o problema - empírico 
ou conceitual - a ser resolvido é a unidade básica da mudança científica. Ao ampliar ao máximo a esfera de problemas empíricos resolvidos e, ao mesmo tempo, ao reduzir ao mínimo o âmbito de problemas anômalos e conceituais, a Geografia estaria alcançando efetivamente seus objetivos como ciência. Outro entendimento importante na epistemologia de Laudan (1977) é o de efetividade global de uma teoria na resolução de problemas. Esta diz respeito à possibilidade de avaliação do número e da importância dos problemas empíricos que uma teoria resolve, subtraindo o número e a importância das anomalias e problemas conceituais que a teoria gera. Há progresso se a sucessão de teorias científicas em um domínio mostra-se crescente de efetividade na resolução de problemas. Quando modificamos uma teoria ou a substituímos por outra, a mudança é progressiva se a versão posterior resolve problemas com mais eficácia do que sua predecessora (LAUDAN, 1977, p. 102).

\section{Problemas Conceituais da Geografia}

Os problemas conceituais estão relacionados ao teor das próprias teorias, podendo ser internos a elas, geralmente surgidos de ambiguidades ou circularidades conceituais e, outros, externos a elas. Apresentam uma ordem de dificuldades que podem ser:

i) intracientíficas - relacionadas a teorias de diferentes domínios que estão em contradição;

ii) normativas - relacionadas a teorias em conflito com teorias metodológicas da comunidade científica;

iii) relativas à visão de mundo - relacionadas a uma teoria em conflito com algum componente da visão de mundo dominante. Na maior parte dos casos, como resultado das tensões entre concepções geográficas, de um lado, e concepções filosóficas, teológicas ou metafísicas de outro (LAUDAN, 1986, p. 88).

Muitos desses problemas condicionam nossas perspectivas em termos de visão de mundo, sendo formulados quando nos questionamos acerca de determinados conceitos, como por exemplo quando se tenta definir (e alcançar) uma sociedade justa. Esses problemas exigem geralmente um embate em torno de ideias e só assim se avança em termos de sua compreensão. Normalmente a reflexão sobre um problema conceitual pode pôr em cheque algumas concepções que consideramos acertadas.

Os problemas conceituais podem ser analisados quando surgem ambiguidades ou circularidades conceituais no âmbito da teoria. Nesse caso, trata-se de problemas internos a ela. Quando, no domínio da teoria, surgem inconsistências com outra teoria aceita, trata-se, nesse caso, de problemas externos.

\section{Problemas Empíricos da Geografia}

Tais problemas estão na ordem das respostas que a Geografia frequentemente procura dar sobre o mundo tal como ele é relativizado pelo saber geográfico. Os problemas 
empíricos são definidos como qualquer coisa acerca do mundo (natural, social, socioambiental) ou das relações entre eles e suas respectivas derivações (trabalho, lazer, exploração, expropriação, impacto, risco, etc.) que nos surpreende como estranha ou que necessita de uma explicação (LAUDAN, 1986, p. 43).

As respostas a tais problemas fundam-se no conjunto das experiências que os tratam, quer seja no âmbito da Geografia, quer seja no cerne das ciências que lhe dão suporte. Normalmente alguns dos principais problemas já têm respostas devidamente fundamentadas nas teorias, mas há problemas que carecem de respostas adequadas, uma vez que a avaliação das teorias é ainda premente porque seus testes são deficientes. Na Geografia a avaliação é feita por meio dos trabalhos de campo, do manuseio de aparelhos e do domínio de técnicas e tecnologias (mapeamento, aplicação de questionários, confecção de planilhas, etc.) que possibilitam o levantamento de dados empíricos e o teste de teorias. Resultam na maior parte das vezes em diferentes tipos de zoneamentos, propostas de planejamento ou de organização espacial e explicações genéricas acerca do fenômeno estudado, na tentativa de promover resolução de problemas. Por vezes, o aparecimento de novos dados faz com que seja necessário rever teorias ou adaptá-las ou mesmo rejeitá-las.

Os problemas empíricos da Geografia não são da ordem de investigação puramente mental, ou seja, não conseguem ser investigados só com o pensamento e também não suportam conclusões sem base experimental. Perguntar quais as alternativas ao desenvolvimento de nações recém-industrializadas num contexto de mundo globalizado é um bom exemplo de problema empírico da Geografia. O mesmo se pode dizer acerca do fato de que se procurou provar no Brasil, com as primeiras cartas sinóticas inteligíveis dos serviços meteorológicos, desde 1916, por meio de uma estatística de tipos de tempo, aumentos sucessivos da circulação geral da atmosfera e das médias de temperatura. Pode-se mencionar ainda como exemplo uma das ordens de problemas empíricos da Geografia econômica e agrária brasileira, pronunciada por vários geógrafos, destacando-se, dentre eles, Pierre Defontaine, a respeito do desgaste promovido por técnicas de cultivo enraizadas na cultura brasileira que levariam inevitavelmente a problemas de ordem econômica e ambiental:

Por espírito de providência, os proprietários cultivam apenas partes de seus domínios e logo que elas dão sinais de cansaço, deixam-n'as e vão roçar mais adiante outro trato de terra, produzindo esta prática a grande imobilização de terras e a devastação excessiva e inquietadora das matas. Com este sistema de cultura quase temporária, verifica-se contudo o esgotamento de propriedades integrais. Fora alguns recantos privilegiados como a planície circundante da cidade de Campos, a maior parte das zonas agrícolas mais antigas tornaram-se decadentes e até às vezes abandonadas. As culturas preciosas, sobretudo o café, localizam-se em terras virgens da faixa pioneira e caminham progressivamente para o interior como ondas que arrebentam em contínuo avanço. (DEFONTAINE, 1939, p. 32)

Os exemplos mencionados tratam de problemas de ordem empírica que os geógrafos da primeira metade do século XX tentavam resolver. Para eles era importante 
obter evidências da existência do problema e propor soluções apresentando seus modelos teóricos.

Ademais, os exemplos mostram que os problemas situados acerca do espaço geográfico brasileiro se diferenciam dos fatos considerados enunciados verdadeiros sobre o mundo, na medida em que há muitos fatos que não suscitam problemas empíricos, dado serem desconhecidos. Problemas empíricos, então, são dependentes da época, ou seja, estão e são relativos ao contexto. Já os fatos, do ponto de vista epistemológico, são considerados atemporais. Inclusive, fatos conhecidos podem não constituir problemas empíricos, pois há a necessidade de se reconhecer sua relevância em um dado momento histórico.

Parte-se, dessa forma, da distinção entre três tipos de problemas empíricos que desafiam a Geografia:

1) problemas não resolvidos - que não foram resolvidos adequadamente por nenhuma teoria;

2) problemas resolvidos - que foram resolvidos satisfatoriamente no âmbito de alguma teoria existente;

3) problemas anômalos - que não foram resolvidos por uma determinada teoria conhecida, mas que são resolvidos por uma ou mais teorias alternativas (ou rivais).

Para Laudan (1977) umas das características distintivas do progresso científico é a transformação de problemas anômalos e não resolvidos em problemas resolvidos. Deve-se indagar, portanto, sobre problemas resolvidos por teorias e pelas anomalias que elas enfrentam. Essa questão se converte em uma das ferramentas fundamentais para a avaliação comparativa das teorias científicas.

Quanto ao status de problema não resolvido, destacam-se, por exemplo, resultados experimentais que são difíceis de reproduzir ou instrumentos de medida que não são confiáveis. Portanto, esse tipo de problema tem um status ambíguo (LAUDAN, 1977, p. 48), uma vez que sua não solução pode ser relacionada à limitação tecnológica da época.

Quanto aos problemas anômalos, considera-se que o aparecimento de uma anomalia suscita dúvidas acerca da teoria que a revela, mas isso não necessariamente implica o seu abandono. Não importa tanto quantas anomalias uma dada teoria gera, mas sim a relevância cognitiva que essas anomalias possuem, ao grau de discrepância entre o resultado experimental observado e a previsão teórica obtida, à sua antiguidade e à sua resistência em ser solucionada pela teoria considerada. A avaliação da relevância dos problemas empíricos é uma questão cognitiva racional, pois a importância da resolução de problemas empíricos (tanto aqueles já resolvidos como os anômalos) não é a mesma em todos os casos, uma vez que alguns deles são de muito maior importância do que outros. Por exemplo, quando ocorre a valorização de um problema por sua solução ou a diminuição de sua importância por sua dissolução. A avaliação da importância de um problema ou de uma anomalia concreta requer também o conhecimento das diversas teorias do domínio e o conhecimento sobre se essas teorias tiveram êxito ou não ao propor soluções. Se um problema não resolvido por uma teoria também não é resolvido por todas as outras teorias do domínio, então esse problema não pode pesar muito na avaliação. Se, ao 
contrário, a teoria não o resolve, mas há outra teoria - rival ou não - que o faz, então o problema constitui uma efetiva anomalia.

\section{A RESOLUÇÃO DE PROBLEMAS POR DIFERENTES TRADIÇÕES DE PESQUISA EM GEOGRAFIA}

Tradição de Pesquisa é uma unidade de análise adotada neste trabalho. As Tradições de Pesquisa têm certo número de teorias específicas, sendo algumas delas contemporâneas e outras sucessoras temporais de teorias anteriores. Toda tradição de pesquisa evidencia compromissos metafísicos e metodológicos que no seu conjunto caracterizam e distinguem-na das outras. Têm, portanto, teorias diferentes e específicas que se desenvolvem numa história que se estende ao longo de um considerável período de tempo. Uma tradição de pesquisa se fecha num conjunto de afirmações e negações de caráter ontológico (objetos de indagação) e metodológico (métodos de indagação), constituindo-se num grupo de pressupostos gerais acerca das entidades e dos processos de um campo de estudo e acerca dos métodos apropriados que devem ser utilizados para investigar os problemas e para construir as teorias do domínio de que se trata.

O conjunto de elementos irrefutáveis de uma tradição de pesquisa varia com o tempo, e a coexistência de Tradições de Pesquisa rivais constitui uma regra no campo da ciência. Dessa forma, a mudança na avaliação das Tradições de Pesquisa envolveria:

i) um aspecto retrospectivo no qual se determinaria por comparação a efetividade na resolução de problemas dentre os conjuntos de teorias que constituem sua versão mais antiga, com a dos que constituem sua versão mais recente;

ii) um aspecto prospectivo, dado por uma taxa extraída das mudanças na adequação momentânea durante um período de tempo específico. O conjunto de elementos momentaneamente de uma tradição de pesquisa varia com o tempo.

Em relação aos contextos nos quais são avaliadas as Tradições de Pesquisa, destacam-se:

i) o contexto da aceitação - no qual os geógrafos decidem aceitar uma tradição de pesquisa entre um grupo de tradições rivais. Trata-se de uma escolha progressiva e racional a partir daquela mais adequada para resolver problemas de interesse;

ii) o contexto de utilização - no qual geógrafos podem ter boas razões para trabalhar em uma tradição de pesquisa que não aceitam (em geral, é o que ocorre com Tradições de Pesquisa novas). São muitos os motivos específicos para seguir uma tradição de pesquisa e estão ligados ao que, na comunidade científica, chama-se de "promessa" ou "fecundidade". É sempre racional seguir qualquer tradição de pesquisa que tenha uma taxa de progresso mais elevada do que suas rivais (mesmo que seu progresso geral acumulado seja menor).

Em síntese, assume-se a seguinte caracterização geral das mudanças na ciência geográfica: 
1) A adequação ou a eficácia das várias teorias depende da quantidade de problemas empíricos importantes que cada qual resolve e da quantidade de problemas conceituais e anomalias que gera. A aceitação dessas teorias está em conexão tanto com sua eficácia quanto com a aceitação de sua tradição de pesquisa associada.

2) A aceitação de uma tradição de pesquisa, por sua vez, está determinada pela eficácia de suas teorias para resolver problemas.

3) A promessa ou possibilidade de utilização racional de uma tradição de pesquisa está determinada pelo progresso geral exibido por ela.

4) A aceitação, o rechaço, a utilização e a não utilização constituem grandes atitudes cognitivas que os geógrafos podem adotar legitimamente com respeito às Tradições de Pesquisa (e suas teorias constitutivas). A determinação da veracidade ou da falsidade é irrelevante para a aceitação ou a viabilidade de teorias e de Tradições de Pesquisa.

5) As avaliações de teorias e de Tradições de Pesquisa têm de ser realizadas em um contexto comparativo. O que importa não é quão efetiva ou progressiva seja uma tradição de pesquisa, mas a eficácia ou caráter progressivo que ela apresenta em comparação com suas rivais, antecessoras, predecessoras ou sucessoras.

Neste trabalho, considera-se que revolução científica, corte epistemológico ou ruptura podem ser categorias básicas para o tratamento da evolução da Geografia, desde que se compreenda que o debate sobre os fundamentos conceituais de qualquer Tradição de Pesquisa ocorre a partir da visão de um processo historicamente contínuo. Revoluções científicas são, portanto, produzidas quando Tradições de Pesquisa até então desconhecidas ou ignoradas pelos geógrafos alcançam um grau de desenvolvimento tal que os mesmos se sentem obrigados a levá-las seriamente em consideração. Em uma dada revolução é possível comparar objetiva e racionalmente as Tradições de Pesquisa rivais a partir de dois levantamentos: o da resolução de problemas e o do progresso da Geografia. Do ponto de vista da resolução de problemas, é possível mostrar teorias explicativas rivais referindo-se a um mesmo problema e, do ponto de vista do progresso (caso em que não se consegue decidir se teorias rivais tratam do mesmo problema), pode-se construir algo como uma graduação progressiva de todas as Tradições de Pesquisa em um dado momento. Seria, assim, possível comparar a progressividade de Tradições de Pesquisa diferentes, inclusive se elas fossem totalmente incomensuráveis.

\section{CONSIDERAÇÕES FINAIS}

Por meio de um modelo intrincado de rede de crenças factuais, metodológicas e valorativas dependentes uma das outras e das mudanças que sofrem ao longo do tempo, pode-se avaliar como ocorrem revisões racionais nos níveis da rede de compromissos científicos da Geografia, quer seja do ponto de vista teórico, metodológico ou dos valores e metas que acompanham a trajetória da disciplina. A contribuição almejada está em 
demonstrar que a relação multifacetada entre teoria, métodos e valores implica que cada um desses níveis pode afetar sua evolução histórica relacionada a uma dada tradição de pesquisa. Busca-se contribuir para a avaliação epistêmica da Geografia.

Ao propor um modelo centrado na resolução de problemas enfatiza-se que uma das metas da Geografia seria, assim, a de ampliar a esfera de problemas empíricos resolvidos ao mesmo tempo em que se procura reduzir o âmbito de problemas anômalos e conceituais. Ainda, pode-se avaliar em termos progressivos se a sucessão de teorias em Geografia mostra um grau crescente de efetividade na resolução de problemas. Quando a teoria é modificada ou substituída por outra, a mudança é progressiva se a versão posterior resolve problemas com mais eficácia do que sua predecessora. Claro é que tal proposição carece de efetivos maiores em termos avaliativos, e desses nos encarregaremos em publicações posteriores.

\section{REFERÊNCIAS}

AGNEW, J.; LIVINGSTONE, D.; ROGERS, A. (Orgs.). Human Geography: an essencial anthology. Blackwell Publishing Ltd: Pedstow, Cornwall, 1996.

CUPANI, A. A Filosofia da Ciência de Larry Laudan e a crítica do positivismo. In: Manuscrito. Campinas, v. XVII, n. 1, p. 91-143, abril, 1994.

DEFONTAINE, P. Geografia Humana do Brasil. In: Revista Brasileira de Geografia, v. 1, Rio de Janeiro, 1939, p. 19-67.

DER VALK, T.V.; VAN DRIEL, J. H.; DE VOS, W. Common characteristics of models in present-day scientific practice. Research in Science Education. v. 37, n. 4, p. 469-488, 2007.

FREEMAN, T. W. A hundred years of geography. Londres: Gerald Duckworth, 1961.

LAUDAN, L. Progress and its problems: toward a theory of scientific growth. Berkeley/Los Angeles/ London: University of California Press, 1977.

1986.

. et al. Science change: philosophical models and historical research. In: Synthess, v. 69, p. 141-223,

LIVINGSTONE, D. (Org.). The geographical tradition. Malden: Blackwell Publishing , 1992.

; WITHERS, C. W. J. (Orgs). Geography and enlightenment. The Ubniversity of Chicago Press, Chicago and London, 1999.

MORAES, A. C. R. de; COSTA, W. M. da. Geografia: pequena história crítica. São Paulo: Hucitec, 1986.

SAEZ, H. C. Filosofia y ciência en la geografia contemporânea. Barcelona: Editorial Barcanova, 1983.

SUPPE, F. La estrutrura de las teorias científicas. Madrid: Nacional, 1979.

Recebido em 09/10/2012

Aceito para publicação em 22/10/2013 